\title{
The Perinatal Beliefs, Practices, and Outcomes Among Badjaos in Dauis, Bohol, Philippines
}

\author{
AIM DANECA B. BERNALDEZ \\ http://0000-0002-4673-0952 \\ aimbernaldez@yahoo.com
}

SHARON M. LUPIO

http://orcid.org/0000-0001-9191-3726

smlupio@universityofbohol.edu.ph

\section{ABSTRACT}

Culture plays a very significant role in the way a woman perceives and prepares her birthing experience. This study aimed to determine the specific cultural perinatal practices and pregnancy outcomes among 30 Badjao women in Totolan, Dauis, Bohol. The respondents were Badjao mothers who had been pregnant and had given birth regardless of age and regardless of pregnancies. A purposive qualitative study was utilized, and data were gathered through group and key informant interviews. The study revealed that practices of the majority in the prenatal period still adhere to the traditional beliefs. It also revealed that majority in the intrapartal and postpartal period still practice traditional beliefs. Many of these beliefs were not beneficial to the health of the mother and the fetus and a growing infant. However, the study also revealed that there were acceptable ways being widely practiced by the Badjao mothers as well. The study further showed that despite the existing traditional practices, records had shown that there were very few records of negative pregnancy outcomes. Still, the negative pregnancy outcomes are a cause for concern. It is safe to say that women who are steeped in traditional cultural beliefs need supportive health educational services to increase their level of knowledge and enhance the recommended health practices. 
Keywords: Nursing care, perinatal beliefs, Badjaos, traditional beliefs, qualitative method, Philippines, Asia

\section{INTRODUCTION}

Pregnancy is a crucial and at the same time a rewarding experience of a mother. Culture plays a major role in the way a woman perceives and prepares for her delivery. Each culture has its values, beliefs, and practices related to pregnancy and birth (Guinean, 2016).

Here in the Philippines, various beliefs and practices about pregnancy are embraced. The Badjaos are one of the minority groups in the country which has established a community in Totolan, Dauis. Since culture has a significant impact on pregnancy, delivery and the postpartum period, the practice of nursing today demands that as a nurse, one must identify and meet the cultural needs of diverse groups and develop the expertise to implement culturally acceptable strategies in providing nursing care that is acceptable to the patient (Sarabi, 2007).

As the researchers observed, the Badjaos have poor access to health services since they usually consult their hilots or panday for health matters and are satisfied with the traditional health practices in their society. Thus, they usually have a poor rate of prenatal check-ups at the local health center. This scenario spurred the researcher to come up with this study to understand their unique culture and traditions so that it may somehow contribute to improving the lives of these indigenous group.

The study drew on Madeliene Leininger's theory on "Transcultural Nursing." Her theory aims to provide culturally congruent nursing care through "cognitively based assistive, supportive, facilitative or enabling acts or decisions that are mostly tailor-made to fit with the individual, group's or institution's cultural values, beliefs, and lifeways. To her, culturally congruent care exemplifies care that fits the people's valued life patterns (Leininger 1988). Moreover, it also corresponds with the theory advocated by Weidenbach "The Helping Art of Clinical Nursing" since this theory conceptualized nursing as a practice of identification of a patient's need for help through observation of presenting behaviors and symptoms (Wiedenbach, 1963).

The Badjao are an indigenous ethnic group of Southeast Asia. They are a nomadic, seafaring people that live off the sea by trading and subsistence fishing. They usually live close to the shore by erecting houses on stilts and 
travel using lepa-lepa handmade boats which many used as their shelters. Badjaos usually resort to "spiritual healing" method for any medical ailments they are experiencing, and they prefer traditional or herbal medicines (Jumala, 2011: 2013). Badjao mothers also observe traditional beliefs and practices during pregnancy and delivery. Among these are a preference for giving birth at home and availing of the services of a panday (or traditional birth attendant) to attend to their pregnancy and childbirth care needs (Sarabi, 2007).

The term perinatal pertains to the period immediately before and after birth. It consists of these periods: prenatal, intrapartal and postpartal. The prenatal period occurs before birth referring both to the care of the woman during pregnancy and fetal growth and development. The intrapartal period refers to the onset of labor up to the delivery of the fetus and placenta. Meanwhile, the postpartal period refers to the time the fetus and the placenta had been delivered up to the sixth week (Pilliterri, 2013).

A study on the "Prenatal Beliefs and Practices of Subanen of Lapuyan, Zamboanga Del Sur" posited that the perinatal practices that the Subanen followed are solely based on the unique beliefs that originated from their ancestors and have been preserved for a long time including the different perinatal practices by the Subanen tribe that are still being practiced to this day (Valdez \& Canapi, 2015).

A study on the "Socio and Cultural Factors in Pregnancy Complications among Navajo Women" found that in a subsample of women and having a controlled variety of conventional risk factors and other potential confounders, traditional women sustained complications at a rate greater than twice than that of the least traditional and most acculturated women. Social support and life events were associated with maternal complications, with poorer outcomes found among those with low social support. It is proposed that relationship of maternal complications to all three sociocultural variablestraditionally, social support, and life events may reflect the influences o social isolation on the course and outcomes of pregnancy. (Boyce, Schaefer, Harrison, Haffner, Lewis, \& Wright, 1986)

Postpartum complication refers to the pathological process or event occurring after delivery. Postpartum hemorrhage refers to excessive blood loss during and after the third stage of labor. It could be caused by uterine atony, lacerations, hematoma, retained placental fragments, Sheehan's syndrome. Another common postpartal complication is puerperial fever or infection, postpartal thromboembolic disorders, postpartum psychiatric 
disorders (Pilleterri, 2013).

A study on the "Beliefs and Practices Regarding Delivery and Postpartum Maternal Morbidity in Rural Bangladesh" showed that maternal deaths usually occur in the postpartal period. The women's beliefs, the causation, and use of traditional health care are explored, and findings suggest the training of traditional birth attendants and training on postpartal care (Goodburn, Gazi \& Chowdhudry, 1995).

A study on the "Perinatal experiences of Punjabi women" described their perinatal life's ways and the traditional beliefs and practices are legalized and incorporated into the Canadian health care context. The study revealed three major categories: the pervasiveness of traditional health beliefs and perinatal period (e.g., lifestyle and rituals), the vital role that family members play in supporting women during their perinatal experiences, and interactions with health professionals, both positive and negative. The study concluded that change is required at the levels of care system and the community to ensure that culturally safe care is provided to immigrant Punjabi women and their families during the perinatal (Grewal, Bhagat, \& Balneaves, 2008).

In Jordan, a study on "Rural Jordanian Mother's Beliefs, Knowledge and Practices of Postnatal Care" revealed that despite being the most modern countries in the Middle East, postnatal care service is still underutilized by rural Jordanian mothers. The findings showed that rural Jordanian mothers depended on the cultural health beliefs and knowledge to perform postnatal practices. Most of them depended on cultural beliefs and practices as a mode of health-seeking behavior, in preference to available health services for the care of their infants. Thus, they need supportive health educational services to increase their level of knowledge and enhance the recommended health practices (Abuidhail, 2014).

A study on "The Pedi Woman's Experiences of Childbirth and Early Parenthood: A Summary of Major Findings" showed that there is a move away from the traditional tribal birth custom towards a highly technological birthing process. Evidence of this comes from the lack of knowledge about traditional custom regarding the handling of placenta and blood from childbirth; the desire for hospital births in a supine position, the lack of desire for assistance about pregnancy, birth or postnatal period from traditional and birth attendants and the increasing dependence on nurses and antenatal clinics for information and assistance during this period (Chalmers, 1988).

A study on "The Transition of Childbirth and Pregnancy among Tribal Women in India: A Grounded Theory" also evaluated the transition from 
home births to hospital births. The women adapted to constant trading off both between desirable and essential - that pertains to traditional homebirth as desirable and the essential by going to the hospital. This transition was shaped by multiple complex factors: 1) Overall economic growth and access to modern medical care influencing women's choices, 2) External context in terms of the international maternal health discourses and national policies, especially incentive schemes for promoting institutional deliveries, 3) Socialization into medical childbirth practices via exposure to many years of free outreach services for child and maternal health, 4) Loss of self-reliance in the community as a consequence of role redefinition and deskilling of the TBAs and 5) Cultural belief that intervention is necessary during childbirth aiding easy acceptance of medical interventions (Sharma, Giri, Christensson, Ramani, \& Johansson, 2013).

\section{RESEARCH METHODOLOGY}

The researchers utilized the purposive qualitative study of research, in particular, ethnography, to determine the specific cultural perinatal practices and pregnancy outcomes among Badjao women in Totolan, Dauis. The data were gathered through interview technique utilizing structured interview guide. The guide questions consisted of three parts; first was on the personal data of the respondents, second on their perinatal beliefs and practices, third, on their postnatal practices and pregnancy outcomes.

There were 30 Badjao women who had been pregnant and had given birth regardless of the following conditions, namely, number of pregnancies, age, and the time of deliveries.

\section{OBJECTIVES OF THE STUDY}

The study aimed to determine the cultural perinatal practices and pregnancy outcomes among the Badjao women. Specifically, the study sought to answer the following:

1. What is the profile of the Badjao women in terms of:

1.1. Age

1.2. Educational Attainment

2. What is the obstetrical history of the respondents in terms of:

2.1. Total number of pregnancies

2.2. Term deliveries and premature deliveries 
2.3. Abortions and Miscarriages

2.4. Causes of Abortions and Miscarriages

2.5. Intrauterine Fetal Deaths

2.6. Place of deliveries

2.7. Birth Attendant

2.8. Frequency of prenatal visit

3. What are the perinatal beliefs and practices among Badjao women during the following periods:

3.1. Prenatal Period

3.2. Intrapartal Period

3.3. Postnatal period

4. What are the common pregnancy outcomes among Badjao women?

\section{RESULTS AND DISCUSSIONS}

A. Profile of the respondents. Most of the respondents were 21 to 25 years of age and never had formal education. It can be gleaned from the findings that Badjao women who were in the ideal age for pregnancy, did not give value to education.

B. The obstetrical history of the respondents revealed that they had three to four total number of pregnancies, the majority were full-term vaginal deliveries who gave birth at home attended by a panday (a birth attendant). There were few known cases of premature deliveries, abortions, miscarriages and intrauterine fetal deaths. Most of the miscarriages and abortions occurred due to malnutrition, and the women were still traditional since they preferred the Panday as the birth attendant and delivered at home.

C. Beliefs and practices of Badjao women during the prenatal period:

Overall, most of the women still adhered to their beliefs and practices during the prenatal period. Practices, such as hilot or massage which are done by the panday were still observed. Massage therapy is the scientific manipulation that improves circulation and reduces the stress of the soft tissues of the body. However, certain areas of the body like the abdomen should not be massaged while pregnant. Thus, a proper consultation was advised. Some conditions such as threatened miscarriage and excessive bleeding are 
contradications of massage therapy.

Other strongly-held beliefs included the assumption that a woman is pregnant when there was an absence of menstrual period during full moon for three consecutive months $(86.67 \%)$; eating a twin banana will result to having twin babies $(80.00 \%)$; and non-cutting of hair because a pair of scissors is associated with caesarian delivery $(76.67 \%)$. These results concur with the study of Sarabi (2007) on the Badjao women in Jolo, Sulu possibly showing that Badjao women in the Philippines tend to observe the same practices regardless of location.

Table 1. Beliefs and practices of Badjao Women during Prenatal Period

$$
(\mathrm{N}=30)
$$

\begin{tabular}{|c|c|c|c|c|c|c|}
\hline \multirow{2}{*}{ ITEMS } & \multicolumn{3}{|c|}{ PRACTICED } & \multicolumn{3}{|c|}{ NOT PRACTICED } \\
\hline & $\mathbf{F}$ & $\%$ & $\mathbf{R}$ & $\mathbf{F}$ & $\%$ & $\mathbf{R}$ \\
\hline $\begin{array}{l}\text { A. BEHAVIOR OF BADJAO PREGNANT } \\
\text { WOMEN }\end{array}$ & & & & & & \\
\hline $\begin{array}{l}\text { 1. Ferns are forbidden in the dwelling because it can } \\
\text { cause poor health to the infant }\end{array}$ & 4 & 13.33 & 14 & 26 & 86.67 & 1 \\
\hline $\begin{array}{l}\text { 2. The pregnant woman bathes on a fishnet when } \\
\text { the moon is out. The child will be brave and will } \\
\text { know his way to the sea }\end{array}$ & 8 & 26.67 & 11 & 22 & 73.33 & 4 \\
\hline $\begin{array}{l}\text { 3. Assumes to be pregnant with the absence of } \\
\text { menstrual period within the full moon of three } \\
\text { consecutive months }\end{array}$ & 26 & 86.67 & 1.5 & 4 & 13.33 & 13.5 \\
\hline $\begin{array}{l}\text { 4. Consults the Panday once she believes she is } \\
\text { pregnant }\end{array}$ & 26 & 86.67 & 1.5 & 4 & 13.33 & 13.5 \\
\hline $\begin{array}{l}\text { 5. One who pays attention to hygiene, the baby } \\
\text { would likely be a girl. However, if neglectful of } \\
\text { one's self, the child is a boy }\end{array}$ & 11 & 36.67 & 8 & 19 & 63.33 & 7 \\
\hline $\begin{array}{l}\text { 6. Lying with the head on the side may cause a } \\
\text { breech delivery }\end{array}$ & 13 & 43.33 & 7 & 17 & 56.67 & 8 \\
\hline $\begin{array}{l}\text { 7. Avoid taking a nap at noontime because the baby } \\
\text { will grow big and will cause difficult labor }\end{array}$ & 7 & 23.33 & 12.5 & 23 & 76.67 & 2.5 \\
\hline 8. Avoid criticizing a person with deformities & 16 & 53.33 & 5 & 14 & 46.67 & 10 \\
\hline $\begin{array}{l}\text { 9. Carries salt when leaving the house to ward off } \\
\text { evil spirits }\end{array}$ & 10 & 33.33 & 9.5 & 20 & 66.67 & 5.5 \\
\hline $\begin{array}{l}\text { 10. Wears dark clothes when going out at night to } \\
\text { pass unnoticed by evil spirits }\end{array}$ & 10 & 33.33 & 9.5 & 20 & 66.67 & 5.5 \\
\hline $\begin{array}{l}\text { 11. Unlocks all locked containers and cabinets for } \\
\text { easy delivery }\end{array}$ & 7 & 23.33 & 12.5 & 23 & 76.67 & 2.5 \\
\hline 12. Avoid sewing clothes for easy delivery & 15 & 50.00 & 6 & 15 & 50.00 & 9 \\
\hline $\begin{array}{l}\text { 13. Prohibiting to sit in the doorway. The position is } \\
\text { associated with a difficult delivery }\end{array}$ & 24 & 80.00 & 3 & 6 & 20.00 & 12 \\
\hline
\end{tabular}




\begin{tabular}{|c|c|c|c|c|c|c|}
\hline $\begin{array}{l}\text { 14. Prohibiting haircut. The scissor signifies cesarean } \\
\text { delivery }\end{array}$ & 23 & 76.67 & 4 & 7 & 23.33 & 11 \\
\hline \multicolumn{7}{|l|}{ B. BEHAVIOR OF THE HUSBAND } \\
\hline $\begin{array}{l}\text { 1. Avoids visiting dead people/corpse because } \\
\text { something bad will happen to the baby }\end{array}$ & 15 & 50.00 & 1.5 & 15 & 50.00 & 1.5 \\
\hline $\begin{array}{l}\text { 2. Restrictions on sexual activity. Sex during } \\
\text { pregnancy will result in a baby with six fingers, } \\
\text { deformed ears }\end{array}$ & 15 & 50.00 & 1.5 & 15 & 50.00 & 1.5 \\
\hline \multicolumn{7}{|l|}{$\begin{array}{l}\text { C. BEHAVIOR OF THE TRADITIONAL BIRTH } \\
\text { ATTENDANT - "PANDAY" }\end{array}$} \\
\hline $\begin{array}{l}\text { 1. Examines the position of the baby by thorough } \\
\text { massaging of the abdomen to know if the baby is } \\
\text { healthy, normal or twins }\end{array}$ & 20 & 66.67 & 1 & 10 & 33.3 & 1 \\
\hline \multicolumn{7}{|l|}{ D. FOOD FADS AND FALLACIES } \\
\hline $\begin{array}{l}\text { 1. Prohibiting to eat bloody fish from dynamite } \\
\text { fishing because it might cause excessive bleeding }\end{array}$ & 16 & 53.33 & 2 & 14 & 46.67 & 2 \\
\hline $\begin{array}{l}\text { 2. Prohibiting to eat coconut fruit. Opening the } \\
\text { coconut resembles cesarean section. }\end{array}$ & 4 & 13.33 & 3 & 26 & 86.67 & 1 \\
\hline 3. Prohibiting to eat twin bananas & 24 & 80.00 & 1 & 6 & 20.00 & 3 \\
\hline \multicolumn{7}{|l|}{ E. REMEDIES FOR COMMON HEALTH PROBLEMS } \\
\hline 1. Fever-drinking water from boiled roots of the tree & 19 & 63.33 & 2 & 11 & 36.67 & 3 \\
\hline $\begin{array}{l}\text { 2. Cough \& Colds-drinking water from boiled } \\
\text { oregano leaves }\end{array}$ & 16 & 53.33 & 3 & 14 & 46.67 & 2 \\
\hline $\begin{array}{l}\text { 3. Body Weakness-boiling a mixture of the sea from } \\
\text { high tide and low tide \& apply to all parts of the } \\
\text { body }\end{array}$ & 13 & 43.33 & 4 & 17 & 56.67 & 1 \\
\hline $\begin{array}{l}\text { 4. Diarrhea-drinking boiled water from guava and } \\
\text { avocado leaves }\end{array}$ & 20 & 66.67 & 1 & 10 & 33.33 & 4 \\
\hline
\end{tabular}

\section{Beliefs and practices of Badjaos during the Intrapartal Period:}

Majority of the respondents claimed that they still embraced their beliefs and practices during this period. A good indicator of this is the fact that more than 86 percent of respondents practiced frequent bathing in the sea. Other traditions include eating danggit $(90.00 \%)$ and cassava tops $(80.00 \%)$ for a quick labor and delivery of the baby. A strange belief is the stopping of any carpentry work during delivery. More than 76 percent of respondents believe that any carpentry work done during this time would signify a difficult delivery.

As to the role of the panday on the process of delivery, most of the pandays still practiced cleansing of the umbilical cord by sliding her finger three times toward the baby and many times toward the placenta with a strong faith that it is necessary to remove the black and red spots to 
ensure a white and clean cord. This practice runs contrary to the Protocol on Essential Newborn Care of the World Health Organization (2014) which states that there should be no milking of the cord towards the baby. After the first clamp, the cord maybe stripped of blood before applying the second clamp. No substance should be applied to the cord. Furthermore, it explains that the "no milking" process helps to reduce anemia in term and preterm, intraventricular hemorrhage (IVH), and transfusions in preterm. Hence, the practice of cord milking done by the pandays is obsolete, and it is not beneficial to the baby.

Table 2. Beliefs and Practices of Badjao Women During Intrapartal Period

$$
(\mathrm{N}=30)
$$

\begin{tabular}{|c|c|c|c|c|c|c|}
\hline \multirow[t]{2}{*}{ ITEMS } & \multicolumn{3}{|c|}{ PRACTICED } & \multicolumn{3}{|c|}{ NOT PRACTICED } \\
\hline & $\mathbf{F}$ & $\%$ & $\mathbf{R}$ & $\mathbf{F}$ & $\%$ & $\mathbf{R}$ \\
\hline A. BEHAVIOR OF THE HUSBAND & & & & & & \\
\hline $\begin{array}{l}\text { 1. The husband/father-to-be keeps a torch burning at the } \\
\text { door to drive away evil spirits that will be attracted to } \\
\text { expelled blood }\end{array}$ & 7 & 23.33 & 2 & 23 & 76.67 & 1 \\
\hline $\begin{array}{l}\text { 2. He should not be present in the hut where the delivery } \\
\text { is taking place }\end{array}$ & 10 & 33.33 & 1 & 20 & 66.67 & 2 \\
\hline B. BEHAVIOR OF BADJAO PREGNANT WOMEN & & & & & & \\
\hline 1. Frequent bathing at the sea & 26 & 86.67 & 1 & 4 & 13.33 & 3 \\
\hline 2. Praying to fairies & 8 & 26.67 & 3 & 22 & 73.33 & 1 \\
\hline 3. Wearing of amulet/ charm, habak & 9 & 30.00 & 2 & 21 & 70.00 & 2 \\
\hline C. THE BIRTHING PROCESS & & & & & & \\
\hline $\begin{array}{l}\text { 1. Covering the floor with woven mat and plastic where } \\
\text { the pregnant women will lie to avoid bloodstain }\end{array}$ & 23 & 76.67 & 3.5 & 7 & 23.33 & 4.5 \\
\hline $\begin{array}{l}\text { 2. Using of malong to cover the hips downward to have } \\
\text { privacy. No one is allowed to see the private parts } \\
\text { even the Panday because if someone does, will } \\
\text { become a bad spirit }\end{array}$ & 27 & 90.00 & 1 & 3 & 10.00 & 7 \\
\hline $\begin{array}{l}\text { 3. Tying a rope to the ceiling to pull strength throughout } \\
\text { the delivery }\end{array}$ & 14 & 46.67 & 7 & 16 & 53.33 & 1 \\
\hline $\begin{array}{l}\text { 4. Position during delivery: recline on the floor with } \\
\text { thighs apart and knees flexed for easy deliver }\end{array}$ & 22 & 73.33 & 5 & 8 & 26.67 & 3 \\
\hline $\begin{array}{l}\text { 5. Only female family members (mother/ sister) can stay } \\
\text { for support }\end{array}$ & 16 & 53.33 & 6 & 14 & 46.67 & 2 \\
\hline $\begin{array}{l}\text { 6. During delivery, carpentry work is prohibited. It } \\
\text { signifies difficult delive }\end{array}$ & 23 & 76.67 & 3.5 & 7 & 23.33 & 4.5 \\
\hline $\begin{array}{l}\text { 7. If delivery takes place during the night, suitable } \\
\text { prayers are made by family members }\end{array}$ & 26 & 86.67 & 2 & 4 & 13.33 & 6 \\
\hline
\end{tabular}




\begin{tabular}{|c|c|c|c|c|c|c|}
\hline $\begin{array}{l}\text { D. THE ROLE OF "PANDAY” ON THE PROCESS OF } \\
\text { DELIVERY }\end{array}$ & & & & & & \\
\hline 1. Does not perform an internal examination & 11 & 36.67 & 7 & 19 & 63.33 & 1 \\
\hline $\begin{array}{l}\text { 2. Only touches the vaginal opening, to feel for the head } \\
\text { of the baby }\end{array}$ & 18 & 60.00 & 3.5 & 12 & 40.00 & 4.5 \\
\hline $\begin{array}{l}\text { 3. The whole process is ritualized by the prayer of the } \\
\text { Panday to ease the pain during delivery, that the baby } \\
\text { be blessed with good health and for the fast recovery } \\
\text { of the mother }\end{array}$ & 19 & 63.33 & 1.5 & 11 & 36.67 & 6.5 \\
\hline $\begin{array}{l}\text { 4. Prayer of the Arm is done by tearing a strip of white } \\
\text { cloth and rolls it to make a cord. After this, it will be } \\
\text { blessed through the blowing of air and prayer then the } \\
\text { Panday ties it on her wrist. }\end{array}$ & 13 & 43.33 & 6 & 17 & 56.67 & 2 \\
\hline $\begin{array}{l}\text { 5. Cutting of the umbilical cord is done by measuring } \\
\text { from the stomach up to the level of anterior fontanel } \\
\text { for long life }\end{array}$ & 15 & 50.00 & 5 & 15 & 50.00 & 3 \\
\hline $\begin{array}{l}\text { 6. When the baby is out, the Panday cleansed the cord } \\
\text { by sliding her finger three times toward the baby and } \\
\text { many times toward the placenta }\end{array}$ & 19 & 63.33 & 1.5 & 11 & 36.67 & 6.5 \\
\hline $\begin{array}{l}\text { 7. Waits for the placenta to be released/expelled before } \\
\text { cutting the umbilical cord }\end{array}$ & 18 & 60.00 & 3.5 & 12 & 40.00 & 4.5 \\
\hline E. FOOD FADS AND FALLACIES & & & & & & \\
\hline 1. Eating danggit makes labor and delivery fast & 27 & 90.00 & 1 & 3 & 10.00 & 4 \\
\hline $\begin{array}{l}\text { 2. Eating balanghuy or Cassava tops for quick labor and } \\
\text { delivery }\end{array}$ & 24 & 80.00 & 2 & 6 & 20.00 & 3 \\
\hline $\begin{array}{l}\text { 3. Squeezing of lemon orange and tomato to the } \\
\text { umbilicus of the baby for easy placental expulsion }\end{array}$ & 13 & 43.33 & 3.5 & 17 & 56.67 & 1.5 \\
\hline $\begin{array}{l}\text { 4. A woman in labor for a long time will be given a } \\
\text { special preparation of coconut oil to drink with the } \\
\text { Panday blessing it, reciting a prayer and blowing over } \\
\text { it. }\end{array}$ & 13 & 43.33 & 3.5 & 17 & 56.67 & 1.5 \\
\hline
\end{tabular}

\section{E. Beliefs and practices of Badjaos during Postnatal Period:}

Most of the Badjao women still embraced their beliefs and practices during the postnatal period. These practices include:

Performing a postpartum bath called sobawan done one day after giving birth and offering to the mother a bony type of fish for the mother to have a fast recovery (100\%); boiling guava leaves for washing the genitals (96.67\%); discarding the colostrum because they believe it is dirty $(86.67 \%)$; and boiling the bark of the coconut tree for the mother to drink to prevent excessive postpartum bleeding $(70.00 \%)$. Other beliefs are bathing the baby with warm water savored with lemon basils after $3-5$ days $(83.33 \%)$ and giving drops of ampalaya juice to the baby to vomit ingested material $(60.00 \%)$. 
This finding agrees with the study of Abuidhail wherein it was found that most rural Jordanian mothers still depended on cultural beliefs and practices as a mode of health-seeking behavior, in preference to available health services for the care of their infants. This is still the case even though Jordan is one of most modern countries in the Middle East (Abuidhail, 2014).

Table 4. Beliefs and Practices of Badjaos During Postnatal Period

$$
(\mathrm{N}=30)
$$

\begin{tabular}{|c|c|c|c|c|c|c|}
\hline \multirow[t]{2}{*}{ ITEMS } & \multicolumn{3}{|c|}{ PRACTICED } & \multicolumn{3}{|c|}{ NOT PRACTICED } \\
\hline & $\mathbf{F}$ & $\%$ & $\mathbf{R}$ & $\mathbf{F}$ & $\%$ & $\mathbf{R}$ \\
\hline \multicolumn{7}{|l|}{ A. RITUAL AFTER CHILDBIRTH } \\
\hline $\begin{array}{l}\text { 1. The placenta is placed in a coconut shell. While } \\
\text { being brought towards the seashore, the bearer will } \\
\text { be called by the household, and he/she should not } \\
\text { look back at them; or else the head of the child will } \\
\text { be facing backward in his/her lifetime. }\end{array}$ & 29 & 96.67 & 2.5 & 1 & 3.33 & 9.5 \\
\hline $\begin{array}{l}\text { 2. Burying the placenta deep enough in the sand } \\
\text { so that animals cannot dig it up. The placenta is } \\
\text { considered the baby's twin \& throwing it away may } \\
\text { cause harm to the infant. }\end{array}$ & 27 & 90.00 & 4 & 3 & 10.00 & 8 \\
\hline $\begin{array}{l}\text { 3. Burying the placenta near the seashore to become a } \\
\text { good swimmer }\end{array}$ & 20 & 66.67 & 9 & 10 & 33.33 & 3 \\
\hline $\begin{array}{l}\text { 4. Giving drops of ampalaya juice to the baby to vomit } \\
\text { ingested material }\end{array}$ & 18 & 60.00 & 10 & 12 & 40.00 & 2 \\
\hline $\begin{array}{l}\text { 5. Bathing the baby initially with seawater followed with } \\
\text { a rinse of fresh water as an initiation to Badjao life }\end{array}$ & 17 & 56.67 & 11 & 13 & 43.33 & 1 \\
\hline $\begin{array}{l}\text { 6. Performing postpartum bath called sobawan that will } \\
\text { be done one day after giving birth and offering to the } \\
\text { mother a bony type of fish for fast recover }\end{array}$ & 30 & 100.00 & 1 & 0 & 0.00 & 11 \\
\hline 7. Boiling the sambong/comfrey leaves for genital wash & 23 & 76.67 & 7 & 7 & 23.33 & 5 \\
\hline $\begin{array}{l}\text { 8. Boiling guava leaves until the sap oozes out } \\
\text { (decoction) for washing the genitals }\end{array}$ & 29 & 96.67 & 2.5 & 1 & 3.33 & 9.5 \\
\hline $\begin{array}{l}\text { 9. Letting the mother drink a native coffee, using } 1 \\
\text { cup of hot water with no sugar to prevent excessive } \\
\text { postpartum bleeding }\end{array}$ & 25 & 83.33 & 5.5 & 5 & 16.67 & 6.5 \\
\hline $\begin{array}{l}\text { 10. Bathing the baby with warm water savored with } \\
\text { Lemon basils after the umbilical cord drops off } \\
\text { typically after } 3-5 \text { days to ward off bad spirits away }\end{array}$ & 25 & 83.33 & 5.5 & 5 & 16.67 & 6.5 \\
\hline $\begin{array}{l}\text { 11. Boiling the bark of the coconut tree for the mother to } \\
\text { drink to prevent excessive postpartum bleeding }\end{array}$ & 21 & 70.00 & 8 & 9 & 30.00 & 4 \\
\hline
\end{tabular}




\begin{tabular}{|l|c|c|c|c|c|c|}
\hline B. BREASTFEEDING & \multicolumn{1}{|c|}{} & & & & & \\
\hline 1. The Colostrum is discarded because it is dirty & 26 & 86.67 & 1.5 & 4 & 13.33 & 5.5 \\
\hline $\begin{array}{l}\text { 2. The baby is not allowed to be breastfed for two days } \\
\text { due to the weak condition of the mother. If the baby } \\
\text { persistently cries he will be breastfed by another } \\
\text { lactating mother }\end{array}$ & 20 & 66.67 & 4 & 10 & 33.33 & 3 \\
\hline $\begin{array}{l}\text { 3. The baby is normally breastfed until the 2nd child } \\
\text { comes along }\end{array}$ & 18 & 60.00 & 6 & 12 & 40.00 & 1 \\
\hline $\begin{array}{l}\text { 4. Weaning the child and giving him/her other foods will } \\
\text { start at about 6-7 years old unless a younger sibling } \\
\text { comes }\end{array}$ & 26 & 86.67 & 1.5 & 4 & 13.33 & 5.5 \\
\hline $\begin{array}{l}\text { 5. Weaning is facilitated by a bitter substance to the } \\
\text { mother's nipples such as ampalaya juice }\end{array}$ & 21 & 70.00 & 3 & 9 & 30.00 & 4 \\
\hline $\begin{array}{l}\text { 6. Children from different biological mother or father, } \\
\text { who suck from the same lactating mother, are not } \\
\text { allowed to marry each other }\end{array}$ & 19 & 63.33 & 5 & 11 & 36.67 & 2 \\
\hline
\end{tabular}

\section{F. Pregnancy Outcomes among Badjao Women. Half of the} respondents claimed that they experienced bleeding. The other half claimed otherwise. On the whole, even though Badjao women were still observing traditional cultural practices, no significant negative outcome was observed and recorded.

Still, the incidence of abortion (20.00\%) and intrauterine fetal deaths $(10.00 \%)$ are a cause for concern. The study of Brugada (2011) revealed that there was a significant relationship between the delivery of prenatal education and pregnancy outcomes.

The findings agree with the study of Boyce, Schaefer, Harrison, Haffner, Lewis \& Wright (1986) that traditional women suffered from complications at a rate greater than twice than that of the least traditional and most acculturated women. Social support and life events were associated with maternal complications, with poorer outcomes found among those with low social support. It is proposed that relationship of maternal complications to all three sociocultural variables-traditionally, social support, and life events, may reflect the influences of social isolation on the course and outcomes of pregnancy.

It is prudent to say that women who are steeped in traditional cultural beliefs need supportive health educational services to increase their level of knowledge and enhance the recommended health practices. 
Table 5. Pregnancy Outcomes Among Badjao Women

$$
\mathrm{N}=30
$$

\begin{tabular}{|l|c|c|c|c|c|c|}
\hline \multirow{2}{*}{\multicolumn{1}{|c|}{ PREGNANCY OUTCOMES }} & \multicolumn{3}{c|}{ OCCURRED } & \multicolumn{3}{c|}{ NOT OCCURRED } \\
\cline { 2 - 7 } & F & $\%$ & R & F & $\%$ & R \\
\hline 1. Bleeding & 15 & 50.00 & 1 & 15 & 50.00 & 7 \\
\hline 2. Puerperal Infection & 11 & 36.67 & 2 & 19 & 63.33 & 6 \\
\hline 3. Postpartum Thromboembolic Disorders & 4 & 13.33 & 6 & 26 & 86.67 & 2 \\
\hline 4. Postpartum Psychiatric Disorders & 8 & 26.67 & 4 & 22 & 73.33 & 4 \\
\hline 5. Abortion & 6 & 20.00 & 5 & 24 & 80.00 & 3 \\
\hline 6. Intrauterine Fetal Death & 3 & 10.00 & 7 & 27 & 90.00 & 1 \\
\hline 7. No Complications at all & 10 & 33.33 & 3 & 20 & 66.67 & 5 \\
\hline
\end{tabular}

\section{CONCLUSION}

Based upon the preceding findings, the following conclusions are drawn:

1. Since the majority of Badjao women were illiterate with no birth records, they were mostly unaware of unhealthy practices that may lead to major complications later on. Hence, malnutrition appeared to be the leading cause of miscarriage or abortion due to lack of knowledge on proper nutrition.

2. A great number still wanted to deliver at the convenience of their own homes, not knowing that in case of any complications, enough facilities were readily available. No baseline data or insufficient information were at hand since throughout the three trimesters, most of them did not give great importance to prenatal visits.

3. Although the majority of them were still clinging to these perinatal practices, the saving factors were that they had term deliveries and had vaginal delivery despite their rare prenatal check-ups (only once during first, second and third trimesters).

4. Noteworthy to mention was the few incidents of bleeding, intrauterine fetal deaths, and abortion/miscarriages despite their clinging to their superstitious beliefs and practices.

5. Although some availed of the healthcare facilities, an overwhelming majority still availed of the services of the Panday instead of a licensed midwife or doctor. The first key persons they go for consultation were the Pandays who may have the experience, but whose practices are not scientifically based. 
6. Some of the practices under the birthing process can be linked with scientific bases even though it differed from the point of view or perception of the Badjaos. Such practices included: covering the floor with woven mat and plastic where the pregnant woman will lie for hygienic reasons; using of malong to cover the hips downward to observe the right to privacy; reclining on the floor with thighs apart and knees flexed to help relax the muscles; and carpentry work is prohibited because the noise could distract the concentration of the laboring women as well as the attention of the birth attendant.

7. There was knowledge deficit regarding child nutrition since most of the mothers still were not aware of the healthful benefits of the colostrum as evidenced by the 86.67 percent who believe that the colostrum should be discarded. It was believed to be dirty or contaminated, when in fact the colostrum strengthens the immune system and its antibiotic properties help to fight against infant diseases and mortality.

8. Badjao women still did not know the benefits of early breastfeeding as attested by their belief of delaying breastfeeding for two days after birth due to the weak condition of the mother. On the contrary, early initiation of breastfeeding promotes mother-baby bonding.

9. Even during these modern days, they still embraced their traditional beliefs and practices during the prenatal, intrapartal and postnatal periods. These practices gave us the impression that they are still very traditional and that they will utilize these rituals to shape their day-to-day activities and major life choices even though some of these rituals may pose health risks.

10. It was very difficult to establish valid data as all information were solely from the respondents themselves. Relevant documents should include complete lists of abortions, miscarriages, and intrauterine fetal deaths with their respective causes, prenatal visits record, and the list of the outcomes or complications.

\section{REFERENCES CITED}

Abuidhail, J. (2014). Rural Jordanian Mothers Beliefs, Knowledge and Practices of Postnatal Care. Quality in primary care, 222, 85-293. Retrieved from https://goo.gl/rusDN6, (accessed last 5 April 2016). 
Boyce, W. T., Schaefer, C., Harrison, H. R., Haffner, W. H., Lewis, M., \& Wright, A. L. (1986). Social and cultural factors in pregnancy complications among Navajo women. American Journal of Epidemiology, 124(2), 242-253. Retrieved from https://goo.gl/rQ5mhW, (accessed last 15 March 2016).

Brugada, A. B. (2011). Delivery of Prenatal Health Education and Pregnancy Outcomes in Selected Aeta Tribes in Bataan. Age (years), 16(20), 6. Retrieved from https://goo.gl/1tkBxR, (accessed last 5 April 2016).

Chalmers, B. (1988). The Pedi woman's experiences of childbirth and early parenthood: A summary of major findings Curationis, 11(1), 12-19. Retrieved from https://goo.gl/vg9Uqa, (accessed last 15 March 2016).

Goodburn, E. A., Gazi, R., \& Chowdhury, M. (1995). Beliefs and practices regarding delivery and postpartum maternal morbidity in rural Bangladesh. Studies in family planning, 22-32. Retrieved from https:// goo.gl/B6E8UX, (accessed last 5 April 2016).

Grewal, S. K., Bhagat, R., \& Balneaves, L. G. (2008). Perinatal beliefs and practices of immigrant Punjabi women living in Canada. Journal of Obstetric, Gynecologic, \& Neonatal Nursing, 37(3), 290-300. Retrieved from https://goo.gl/GMYdet, (accessed last 15 March 2016).

Guinean, P. (2016). Cultural Dimensions of Pregnancy, Birth and Postnatal Care. Retrieved from https://goo.gl/N8Bjb5, (accessed last 15 March 2016).

Jumala, F. C. (2011). From Moorage to Village: a glimpse of the changing lives of the Sama Dilaut. Philippine Quarterly of Culture and Society, 39(2), 87-131. Retrieved from https://goo.gl/63VPG7, (accessed last 8 April 2016).

Leininger, M. M. (1988). Leininger's theory of nursing: Cultural care diversity and universality. Nursing science quarterly, 1(4), 152-160. Retrieved from https://goo.gl/mVYAiU, (accessed last 15 March 2016). 
Pillitteri, A. (2013). Study Guide to Accompany Maternal and Child Health Nursing. Lippincott Williams \& Wilkins.

Sarabi, R. (2007). Prenatal Beliefs and Practices Among Badjao in Jolo, Sulu. Ateneo De Zamboanga Univesrity, Zambianga, Philippines. Retrieved from https://goo.gl/Uk79RF, (accessed last 15 March 2016).

Sharma, B., Giri, G., Christensson, K., Ramani, K. V., \& Johansson, E. (2013). The transition of childbirth practices among tribal women in Gujarat, India-a grounded theory approach. BMC international health and human rights, 13(1), 41. Retrieved from https://goo.gl/jNYqgj, (accessed last 5 April 2016).

Valdez, A. V., \& Canapi, S. (2015). Healing Beliefs and Practices among Subanen and Mansaka. International Journal of Social Science and Humanity, 5(1), 100. Retrieved from https://goo.gl/KDKhJK, (accessed last 15 April 2016).

Wiedenbach, E. (1963). The helping art of nursing. AJN The American Journal of Nursing, 63(11), 54-57. Retrieved from https://goo.gl/k4ir2L, (accessed last 7 April 2016).

World Health Organization. (2014). Early essential newborn care: clinical practice pocket guide. Retrieved from https://goo.gl/WuBeng, (accessed last 13 March 2016). 